\title{
Epithelial to Mesenchymal Transition in Human Skin Wound Healing Is Induced by Tumor Necrosis Factor- $\alpha$ through Bone Morphogenic Protein-2
}

\author{
Chunli Yan, ${ }^{*}$ Wesley A. Grimm, ${ }^{*}$ \\ Warren L. Garner, ${ }^{*}$ Lan Qin, ${ }^{\dagger}$ Taryn Travis, ${ }^{*}$ \\ Neiman Tan, ${ }^{\star}$ and Yuan-Ping Han ${ }^{\star \dagger \ddagger}$ \\ From the Departments of Surgery, ${ }^{*}$ and Pathology, ${ }^{*}$ and the \\ Graduate Program of Systems Biology and Diseases, ${ }^{\dagger}$ the Keck \\ School of Medicine, University of Southern California, Los Angeles, \\ California
}

Epithelial-mesenchymal transition (EMT), characterized by loss of epithelial adhesion and gain of mesenchymal features, is an important mechanism to empower epithelial cells into the motility that occurs during embryonic development and recurs in cancer and fibrosis. Whether and how EMT occurs in wound healing and fibrosis in human skin remains unknown. In this study we found that migrating epithelial cells in wound margins and deep epithelial ridges had gained mesenchymal features such as vimentin and FSP1 expression. In hypertrophic scars, EMTrelated genes were elevated along with inflammatory cytokines, indicating a causal relationship. To reconstitute EMT in vitro, normal human skin and primary keratinocytes were exposed to cytokines such as tumor necrosis factor- $\alpha$ (TNF- $\alpha$ ), resulting in expression of vimentin, FSP1, and matrix metalloproteinases. Moreover, TNF- $\alpha$-induced EMT was impaired by antagonists against bone morphogen proteins (BMP) $2 / 4$, suggesting that BMP mediates the TNF- $\alpha$-induced EMT in human skin. Indeed, TNF- $\alpha$ could induce BMP-2 and its receptor (BMPR1A) in human skin and primary keratinocytes, and BMP2 could induce EMT features in skin explants and primary keratinocytes. In summary, we uncovered EMT features in both acute and fibrotic cutaneous wound healing of human skin. Moreover, we propose that the mesenchymal induction in wound healing is motivated by TNF- $\alpha$, in part, through induction of BMP. (Am J Pathol 2010, 176:2247-2258; DOI: 10.2353/ajpath.2010.090048)

Epithelial to mesenchymal transition (EMT) was originally described as a mechanism to form primary mesenchymal cells in mesoderm from primitive epithelium during gastrulation in the early embryo. ${ }^{1}$ Then, the concept was substantially expanded to phenotypic alternations or plasticity of epithelial lineages in adult tissues, resulting in loss of cell-cell adhesion and apical-basal polarity, and gain of mesenchymal features including enhanced motility and cytoskeletal rearrangement. ${ }^{2}$ Growing evidence in clinical observations and animal models has exhibited widespread relevance of EMT in the chronic diseases such as fibrosis and tumor progression. ${ }^{3}$ The common features among these chronic diseases are that the transformed or activated epithelial cells are detached, produce matrix-degrading proteolytic enzymes, and even exhibit fibroblasts-like characteristics. ${ }^{4,5}$

The essence of cutaneous wound healing is to restore the epidermal barrier to the external environment during a process called re-epithelialization. ${ }^{6}$ A key feature of reepithelialization is movement or migration of the epithelial sheets under stimulation of injury signals. ${ }^{7}$ We speculated that stationary keratinocytes in human skin may be activated and mobilized in wound healing in a manner that is reminiscent of EMT, which is orchestrated by injury signals such as inflammatory cytokines. Whether and how EMT contributes to normal and fibrotic skin wound healing in humans is still elusive. To investigate these possibilities, we examined acute wounds at the phase of re-epithelialization and hypertrophic scars in the growth phase for those epithelial cells having attained mesenchymal markers. The EMT characteristics were tightly associated with persistent inflammation, indicating a possible causative induction. This led us to test a panel of cytokines for their capacities to induce EMT in explanted human skin and primary human keratinocyte cultures.

Supported by grants from the National Institutes of Health (AR051558 and DK069418 to Y.-P.H.) and Robert May Wright Foundation (to Y.-P.H.). Real-time RT-PCR was conducted in the USC Research Center for Liver Diseases, supported by NIH grant DK048522.

Accepted for publication January 19, 2010

Supplemental material for this article can be found on http://ajp. amjpathol.org.

Address reprint requests to Yuan-Ping Han, Ph.D., 2011 Zonal Ave. HMR813, Los Angeles, CA 90033. E-mail: yhan@surgery.usc.edu. 
Based on this rationale we uncovered that tumor necrosis factor- $\alpha$ (TNF- $\alpha$ )-induced EMT in human skin is mediated, in part, by induction of bone morphogen protein (BMP) 2.

\section{Materials and Methods}

TNF- $\alpha$, transforming growth factor (TGF)- $\beta$, BMP-2, noggin, gremlin, and interleukin (IL)-1 were purchased from R\&D Systems (Minneapolis, MN). Antibodies against Ecadherin and cortactin were from Santa Cruz Biotechnology (Santa Cruz, CA), antibodies for FSP1 and pancytokeratin were from Dako (Carpinteria, CA). Antibodies for vimentin and type-IV collagen were purchased from Chemicon (Temecula, CA). Cy3 conjugated anti-rabbit $\mathrm{IgG}$, fluorescein isothiocyanate-conjugated anti-mouse IgG, and Cy3-conjugated phalloidin were purchased from Sigma-Aldrich (St. Louis, MO). Keratinocyte growth medium (Epilife, with HKGS [growth medium, with pituitary bovine extracts] or EDGS [growth medium, with defined Growth Supplement] supplements), Dulbecco's modified Eagle's medium (DMEM), Superscript II Reverse Transcriptase, trypsin inhihbitor, and Trizol were purchased from Invitrogen (Carlsbad, CA).

\section{Tissues and Cells}

All human skin tissues were collected according to the protocol approved by the Institutional Review Board at the University of Southern California. Hypertrophic scars and normal skin were selected by experienced plastic surgeons and removed as part of reconstructive procedures. Adult epithelial cells were isolated from normal human skin by two protocols. In the first protocol the partial thickness skin was explanted on plastic and cultured in DMEM with 10\% FBS for 4 to 5 days. The migrating keratinocytes were harvested by trypsin treatment and subcultured by keratinocyte growth medium. In the second protocol, partial thickness human skin was incubated in $25 \mathrm{mmol} / \mathrm{L}$ EDTA in DMEM with the epidermis facing down at $37^{\circ} \mathrm{C}$ for 2 to 3 hours. The epithelial sheet was separated using forceps and further digested in $0.5 \%$ trypsin in DMEM at $37^{\circ} \mathrm{C}$ for 0.5 hours. Tissue suspension was filtered through a cell strainer (BD Bioscience). The passed cell suspension was mixed with DMEM containing 10\% FBS or trypsin inhibitor (Invitrogen). Cells were collected by centrifugation at $800 \mathrm{~g}$ for 5 minutes. Keratinocytes were cultured in complete medium, supplemented with HKGS containing streptomycin sulfate (100 $\mu \mathrm{g} / \mathrm{ml}$ ) and penicillin (100 units $/ \mathrm{ml})$. Neonatal human keratinocytes were purchased from Invitrogen and cultured under similar conditions. For organ culture of explants, normal human skin was processed by removal of subcutaneous fats and connective tissue. Pieces $(\sim 100 \mathrm{mg})$ of full thickness skin were floated in DMEM with TNF- $\alpha(5 \mathrm{ng} / \mathrm{ml})$, TGF- $\beta(1 \mathrm{ng} / \mathrm{ml})$, and BMP-2 (40 ng/ml) individually in $2 \%$ FBS at $4^{\circ} \mathrm{C}$ for 18 hours to allow cytokine penetration, then the plates were gradually moved to $37^{\circ} \mathrm{C}$ cell culture incubator with $5 \% \mathrm{CO}_{2}$ for 24 hours. After experiment, skin tissues were briefly fixed in $2 \%$ formalin for 30 minutes, and embedded in OCT compound (Sakura Tissue-Tek, Torrance, $\mathrm{CA}$ ) and stored at $-80^{\circ} \mathrm{C}$.

\section{Immunofluorescence}

Frozen sections were cut to $5 \mu \mathrm{m}$, blocked by $5 \%$ nonfat skim milk, and incubated with monoclonal anti-vimentin antibody at 1:200, polyclonal anti-pan-cytokeratin antibody at 1:400, polyclonal anti-E-cadherin antibody at 1:50, polyclonal anti-FSP-1 antibody at 1:400, polyclonal anti-cortactin antibody at 1:200, or monoclonal anti-type IV collagen antibody at 1:200 in 1\% nonfat milk overnight at $4^{\circ} \mathrm{C}$. Sections were washed with PBS containing $0.1 \%$ Tween20. To detect primary antibodies, sections were incubated with fluorescein isothiocyanate-conjugated anti-mouse-IgG at 1:200 (for vimentin and type IV collagen), Cy3-congugated anti-goat-lgG at 1:400 (for E-cadherin), Cy3-conjugated anti-rabbit-lgG (for pan cytokeratin, cortactin, and FSP-1) at 1:400 (Sigma Aldrich, St. Louis, MO). Diamidino-2-phenylindole dihydrochloride (1 $\mu \mathrm{g} / \mathrm{ml}$ ) was used to stain nuclei.

\section{Histology}

Formalin-fixed skin specimens were embedded in paraffin. Five- $\mu$ m-thick sections were cut and stained with either Hematoxylin-Eosin or Sirius red. Sirius red sections were later visualized under polarized light for birefringence.

\section{Western Blot}

For Western blotting, $50 \mu \mathrm{g}$ of total protein was separated on a $15 \%$ SDS-PAGE under reducing condition. Thereafter, protein was transferred to PVDF-membrane (Millipore, Billerica, MA) and incubated in NT-Tween20 with $5 \%$ skim milk (NT-Tween20: 100 mmol/L NaCl, 50 mmol/L Tris-HCl, pH 7.4 and $0.05 \%$ Tween-20). Membranes were incubated with anti-vimentin antibodies at 1:1000, or anti-FSP1 antibodies at 1:1000, and anti-GAPDH at 1:2000, followed by incubation with the appropriate HRP-conjugated secondary antibodies at 1:2000 and development using Supersignal blotting kit (Thermo-Fisher, Waltman, MA.).

\section{Real-Time RT-PCR}

Total RNA was extracted using Trizol reagent according to the manufacturer's instructions. First-strand cDNA was produced using First-Strand cDNA Synthesis by Superscript II Reverse Transcriptase with random primers (Promega, Madison, WI). One microgram of total RNA was used for each reverse transcription reaction mixture (20 $\mu$ l). Real-time PCR was performed using the ABI Prism $7900 \mathrm{HT}$ (Applied Biosystems, Carlsbad, CA). Ten- $\mu$ reactions were set in 384-well PCR plates using the final concentrations: $1 \mu \mathrm{mol}$ forward and reverse primers, $1 \mathrm{X}$ SYBR Green master mix (Eurogentec, San Diego, CA), and 5 to $10 \mathrm{ng}$ of cDNA. For each condition triplicates were used to minimize variations attributable to pipetting error. Cycling conditions included: an initial step $\left(50^{\circ} \mathrm{C}\right.$ for 2 minutes), hot activation $\left(95^{\circ} \mathrm{C}\right.$ for 10 minutes), amplification $\left(95^{\circ} \mathrm{C}\right.$ for $15 \mathrm{~s}, 60^{\circ} \mathrm{C}$ for 1 minute) repeated 40 times, and quantification by SYBR Green fluorescence measurement. Data were analyzed using the ABI Prism 
Table 1. Real-time RT-PCR primers

\begin{tabular}{|c|c|c|c|}
\hline Gene & Sequence & Primer size & $\operatorname{Tm}\left({ }^{\circ} \mathrm{C}\right)$ \\
\hline \multirow[t]{2}{*}{$T N F-\alpha$} & F: 5'-AAGCCTGTAGCCCATGTTGTA-3' & 21 mer & 52 \\
\hline & $\mathrm{R}:$ 5'-TCAGCTCCACGCCATTG-3' $^{\prime}$ & 17 mer & 49 \\
\hline \multirow[t]{2}{*}{ MMP-9 } & F: 5'-GGGAGACGCCCATTTCG-3' & 17 mer & 52 \\
\hline & 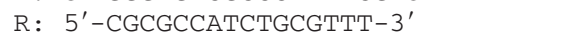 & 16 mer & 49 \\
\hline \multirow[t]{2}{*}{$M M P-13$} & F: 5'-CAGACTTCACGATGGCATTGC-3' & 21 mer & 54 \\
\hline & R: $5^{\prime}$-AGGAAAAGCATGAGCCAGCA-3' & 20 mer & 52 \\
\hline \multirow[t]{2}{*}{ Collagen I } & $\mathrm{F}:$ 5'-CAGCCGCTTCACCTACAGC-3' $^{\prime}$ & 19 mer & 55 \\
\hline & $\mathrm{R}:$ 5'-TTTTGTATTCAATCACTGTCTTGCC-3' $^{\prime}$ & 25 mer & 53 \\
\hline \multirow[t]{2}{*}{$\alpha-S M A$} & $\mathrm{~F}: 5^{\prime}$-CGTGGGTGACGAAGCACAG-3' & 19 mer & 55 \\
\hline & $\mathrm{R}: 5^{\prime}$-GGTGGGATGCTCTTCAGGG-3' & 19 mer & 55 \\
\hline \multirow[t]{2}{*}{ Twist-1 } & F: 5'-TGAGCAACAGCGAGGAAGAGC-3' & 22 mer & 52 \\
\hline & R: 5'-TGAATCTTGCTCAGCTTGTCCG-3' & 22 mer & 50 \\
\hline \multirow[t]{2}{*}{ Slug } & F: 5'-ACAAGCAGCTGCACTGTGAT-3' & 20 mer & 55 \\
\hline & 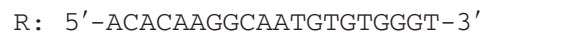 & 20 mer & 55 \\
\hline \multirow{2}{*}{ E-cadherin } & $\mathrm{F}: 5^{\prime}-\mathrm{ACAACAAGCCCGAATTCACCCA-3^{ \prime }}$ & 22 mer & 55 \\
\hline & R: 5'-TCACAGCTGTTGCTGTTGTGCT-3' & 22 mer & 55 \\
\hline \multirow[t]{2}{*}{ N-cadherin } & $\mathrm{F}:$ 5'-TCATTGCCATCCTGCTCTGCAT-3 & 22 mer & 55 \\
\hline & R: 5'-AGTTGTTTGGCCTGGCGTTCTT-3' & 22 mer & 55 \\
\hline \multirow[t]{2}{*}{ Vimentin } & 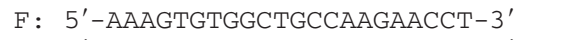 & 22 mer & 55 \\
\hline & 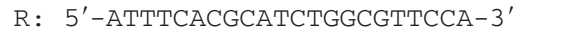 & 22 mer & 55 \\
\hline \multirow{2}{*}{ BMP2 } & 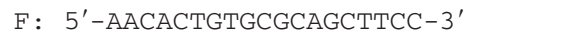 & 19 mer & 55 \\
\hline & $\mathrm{R}: 5^{\prime}$-CTCCGGGTTGTTTTCCCAC-3' & 19 mer & 55 \\
\hline \multirow[t]{2}{*}{ GAPDH } & F : 5'-GAAGGTGAAGGTCGGAGT-3' & 18 mer & 50 \\
\hline & R: 5'-GAGATGGTGATGGGATTTC-3' & 20 mer & 50 \\
\hline
\end{tabular}

SDS 2.3 software. Gene expression was calculated by the $\triangle \mathrm{Ct}$ method, each mRNA was normalized to GAPDH mRNA. Primer sequences are listed in Table 1.

\section{Statistical Analysis}

Data were expressed as means \pm SEM. The data were analyzed by one-way analysis of variance. Significant differences were accepted when two-tailed $t$ test analysis yielded $P<0.05$.

\section{Results}

\section{Epithelial Cells at the Migrating Tongue of Wound Margin Acquire Mesenchymal Features}

We reasoned that during re-epithelization phase, the epithelial cells in the migrating tongue may be mobilized through gain-of-mesenchymal features, and we further speculated such partial EMT may be induced by injury signals such as inflammatory cytokines. We initially evaluated human skin tissues from acute wounds in the phase of re-epithelialization. The biopsies were harvested between 10 and 15 days after thermal burn. Histology of a typical biopsy, of six representative patients, is shown in Figure 1 in H\&E staining. Active ongoing reepithelialization is evident by the migrating tongues of epithelial sheets at both sides of the wound margin (white arrows Figure 1A). In these specimens we found epithelial cells that had undergone EMT, defined as the epithelial cells superficial to the basement membrane zone (BMZ), which gained mesenchymal markers such as fibroblast-specific protein 1 (FSP1) and/or vimentin. At the migration tongues of wound edges, those epithelial cells exclusively expressed FSP1 (Figure 1B). In contrast, the parenchymal epithelial cells distant from the wound edges in spinous and granular layers were clearly lacking the mesenchymal markers. Granulation and inflammation in the center of wound were indicated by massive angiogenesis, infiltrated lymphocytes, and matrix metalloproteinase (MMP)-positive cells (Figure 1C and data not shown).

Not observed in normal human skin, deep rete ridges of extended epidermis were often observed in juxtaposing wound centers. Most epithelial cells in deep rete ridges were FSP1 positive (Figure 1, D and E), and some epidermal cells adjacent to BMZ were vimentin/FSP1copositive. BMZ, as evaluated by immuno-fluorescent staining of type IV collagen in this region, was partially disassembled, which is intimately associated with EMT inductions (Figure 1, F and $\mathrm{G}$ ). In contrast, intact and continuous BMZ was found in the distal normal region. Taken together, these results underscore a possible mechanism to activate epithelial cells in wound healing, by which epithelial cells acquire mesenchymal machinery to fulfill their roles in cell migration and interactions with dermal cells.

\section{EMT Characteristics in Hypertrophic Scars Are Associated with Persistent Inflammation and Fibrosis}

After demonstrating EMT features in acute wound healing, we evaluated the association of EMT with inflammation and fibrogenesis in human hypertrophic scars. An active hypertrophic scar is denoted by the presence of infiltrating lymphocytes and numerous antigen-presenting cells. ${ }^{8}$ Active scars are also characterized by their elevated appearance consisting of thick epithelium and condensed dermis with ample myofibroblasts and interstitial matrix fibers. We compared active hypertrophic 
A

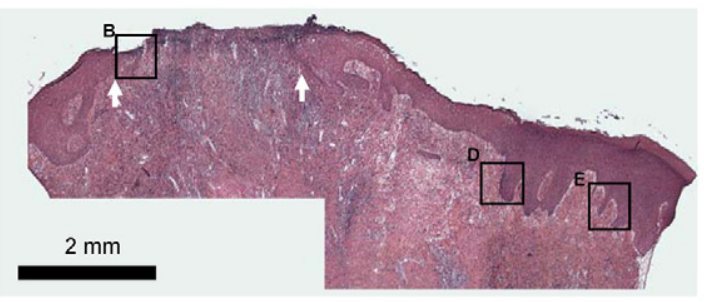

C

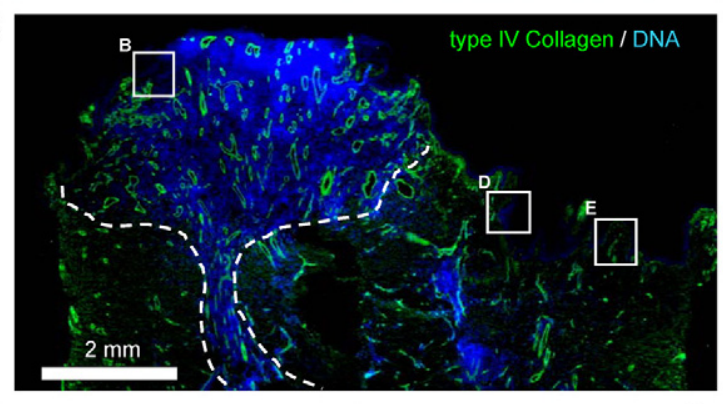

E

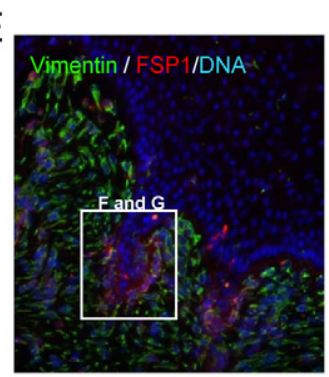

$\mathrm{F}$

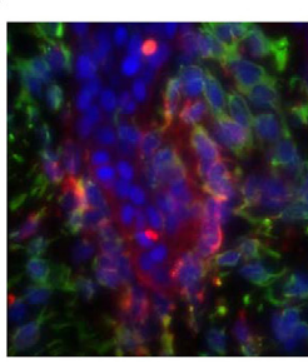

B
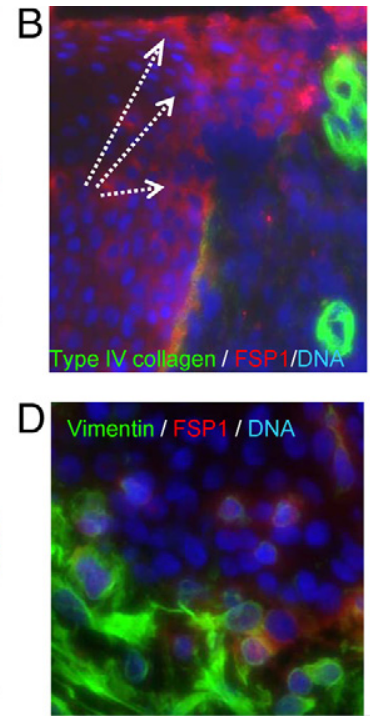

$\mathrm{G}$

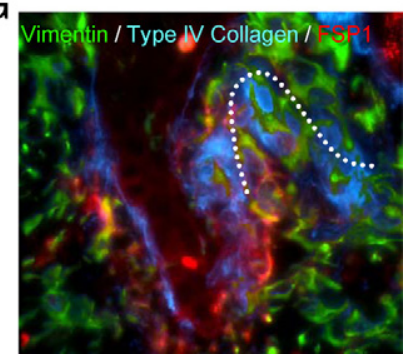

Figure 1. EMT characteristics in reepithelization. A: Typical reepithelization of cutaneous wound healing of thermal burn patients is illustrated by H\&E staining. White arrows indicate the wound bed. The interior box in $\mathbf{B}, \mathbf{D}$, and $\mathbf{E}$ are designated for the regions of migration tongue and adjacent deep ridges, respectively, and illustrated in $\mathbf{B}, \mathbf{D}$, and $\mathbf{E}$, accordingly. $\mathbf{B}$ : Epithelial cells in migrating tongues are indicted by their positions above the BMZ (type-IV collagen immunoflorescent staining, green). The trend of migration is highlighted by white dashed arrows. Gain of mesenchymal features by the epithelial cells in the migration tongues is demonstrated by FSP1 expression (IF staining, red). Nuclei DNA are stained by DAPI in blue. C: Granulation (dashed lines), as marked by cell proliferation (DNA, blue) and angiogenesis (IF staining, type-IV collagen, green), is evident in the reepithelization phase. D-F: Gain of mesenchymal features by the epithelial cells in the deep ridges of epidermis adjacent to wound center is demonstrated by FSP1 and vimentin expression. The EMT features are absent in the epithelial cells of spinous and granular layers. G: The wrecked BMZ at the endings of deep ridges is indicated by discontinued IV collagen stained (IF, blue and the dotted line). scars to the normal part (distal region) of the same donors. H\&E staining portrayed the landscape of a typical human hypertrophic scar, of more than six specimens (Figure 2A). For analytical purposes a typical scar was divided into normal, intermediate, and scar regions. The scar region was then subdivided into marginal, inflammatory, and central regions. In the inflammatory scar region, the rete epithelium was highly convoluted and extended deep into the dermis (red bar in Figure 2A), where a black arrowhead indicates an inflammatory nodule. In contrast, in the marginal, intermediate, and normal regions the epithelium was much less convoluted. Sirius red staining illustrated the differences in condensed collagen bundles within the scar and normal regions (Figure 2B). Clearly, a dense dermal matrix was characteristic in the scar region (white circle in Figure 2B). As expected, increased FSP1positive cells were observed in the epidermis and dermis of the scar region (Figure 2C). Finally, using qRT-PCR we measured the inflammatory, fibrotic, and EMT-related genes and their association with developing stage of fibrosis. Six sets of samples from normal skin and scars were measured (Figure 2D). Among the inflammatory group, TNF- $\alpha$, MMP-9, and MMP-13 were significantly increased 2-, 14-, and 8-fold, respectively, in the scars compared normal skin. The classic fibrotic markers, type-I collagen and $\alpha$-smooth muscle actin, were elevated 8- and 2-fold, respectively, in the scars versus normal skin. Finally, the EMT-related transcription factors slug and twist-1 were significantly expressed in the scars. However, E-cadherin, which is down-regulated in EMT of many epithelial cells cultured in vitro, is not sig- nificantly reduced at global level in the scar tissues, the fact that is explained by epithelial hypertrophy, which may compensate globally for the loss of E-cadherin in defined EMT locus. In contrast, gain of mesenchymal markers such as vimentin and $\mathrm{N}$-cadherin was clearly increased in the scars. Together, these results demonstrate a clear association between unresolved inflammation and persistent EMT features in the developing scars, indicating a possible causal relationship.

\section{Gain of Mesenchymal Features by the Epithelial Cells in Hypertrophic Scars}

To elaborate the features of EMT in hypertrophic scars from thermal burns we examined additional biopsies from hypertrophic scars and normal skin. The hypertrophic scars in the analysis varied from 6 to 24 months after burn injury, and were in their growth phase as judged by their raised erythematous appearance and stiffer consistency than the surrounding skin. The normal skin was from patients undergoing cosmetic or reconstructive surgery. Epithelial cells were characterized by E-cadherin expression (red) or pan-keratin (not shown), and mesenchymal features were defined by vimentin, mostly found in the cells within dermis of normal skin (Figure 3A). In contrast, vimentin-positive epithelial cells were frequently found in the thickened epidermis of hypertrophic scars, but were absent from normal skin (Figure 3, B and C). Importantly, those vimentin-positive cells are simultaneously lacking of E-cadherin, a mutually excluding feature in the classic 

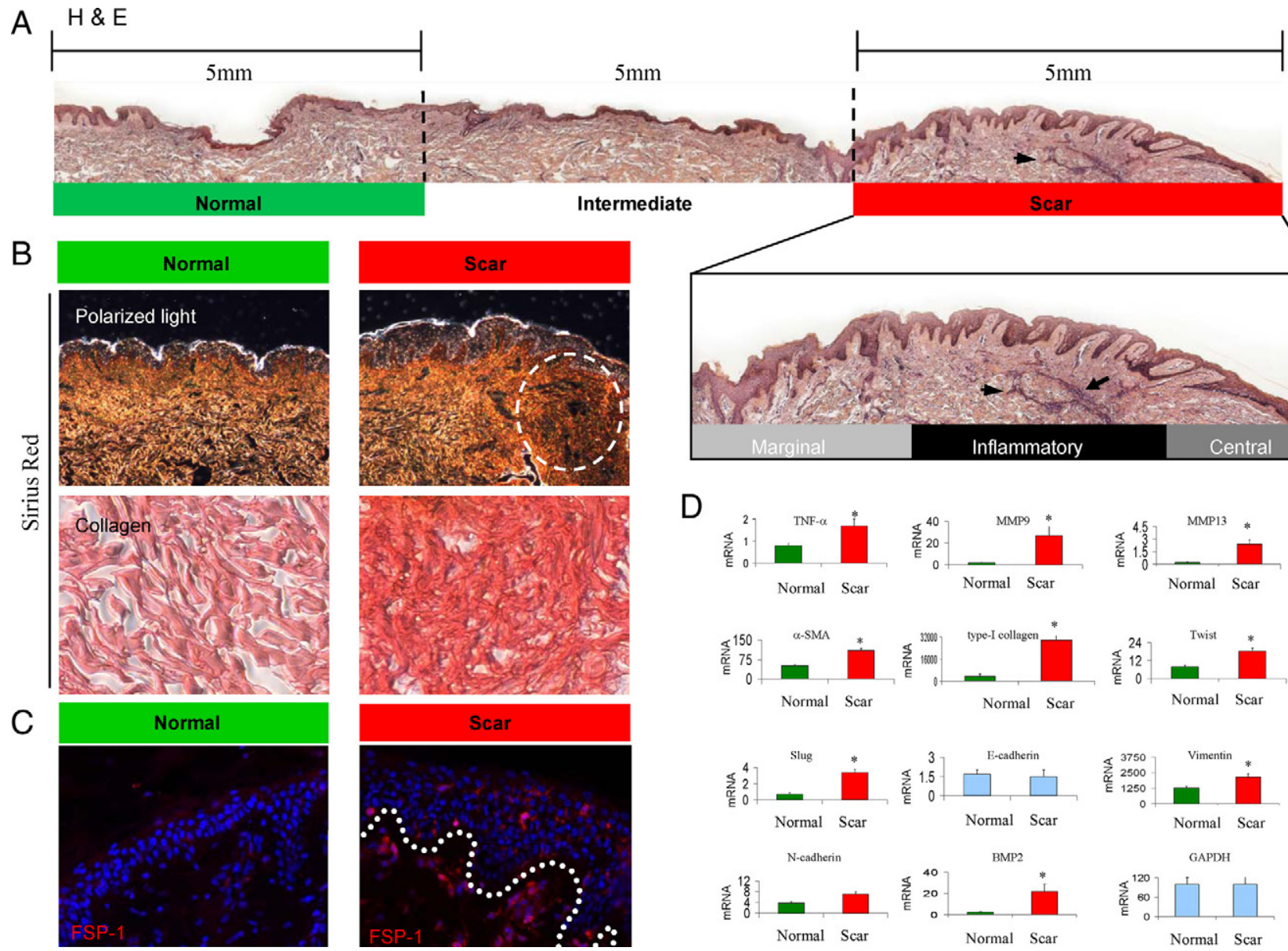

Figure 2. EMT characteristics in hypertrophic scars are associated with unresolved inflammation. A: A representative biopsy containing both hypertrophic scars anc normal skin from the same donors is revealed in H\&E staining. Black arrowheads indicate an apparent inflammatory locus within the scar region. The specimen is divided into three regions for analytical purposes as "normal ( $5 \mathrm{~mm}$ apart from scar epicenter)," "intermediate (within $5 \mathrm{~mm}$ to scar epicenter)," and "scar (as indicated by hypotrophy and convolution of epidermis as well as dense dermal ECM)." The scar region was further divided as "margin," "inflammatory," and "central" regions. B: Tissue fibrosis in the regions of hypertrophic scar is detected by Sirius red staining, as indicated by intense red color in comparison with the normal region. Polarized light in birefringence illustrates fibrotic ECM within the scar region. Dense and disorganized collagen bundles are within the scar region (dash lined circle). C: Gain of mesechymal characteristics by the epithelial cells in hypertrophic scars is indicated by FSP1 expression in epidermis (IF staining, red). The BMZ is indicated by a white dotted line. D: Gene expressions, related to EMT (twist, slug, E-cadherin, and N-cadherin), inflammation (TNF- $\alpha$, MMP-9, MMP-13), and fibrosis (type-I collagen, $\alpha$-SMA, and fibronectin), in the hypertrophic scars and normal skin ( $n=6$ for each group) are measured by real-time qRT-PCR analysis. The expression levels are normalized by mRNA of GAPDH. ${ }^{*} P<0.05$ as significance by Student $t$ test.

definition of EMT. Second, the EMT-positive epithelial cells were in proximity to $\mathrm{BMZ}$, indicating that they are activated cells in suprabasal layer. Similar to the observation in acute wound healing as shown in Figure 1, the well-developed deep epidermal rete ridges were also often found adjacent to wound bed, which were absent from normal skin, indicated by H\&E staining (Figure 3, D and E). Scattering of epithelial cells is a typical feature of classic EMT. Indeed, many of the suprabasal cells in the scar regions were apparently detached from BMZ (green arrows in Figure 3E). Convolution of epithelial sheets was often observed in hypertrophic scars, by which twisted $\mathrm{BMZ}$ had been built inside the epithelia sheets and the cells inside the convolution compartment were mesenchymal positive (see Supplemental Figure 1 at http:// ajp.amjpathol.org). EMT has been tightly associated with extracellular matrix (ECM) degradation and MMP production, particularly in metastasis as a mechanism of extravasations. ${ }^{9}$ Therefore, we assessed the potential breakdown of BMZ in hypertrophic scars and association with EMT. In several specimens we found discontinuous and apparently disassembled BMZ in scar regions, but not in normal skin (Figure 3F). Moreover, the FSP1-positive cells were apparently penetrating across the broken BMZ (Figure 3G). In note, those FSP1-positive cells are actively producing MMPs, which will be discussed later. These findings suggest the possible ingression of the mesenchymal-featured epithelial cells into the dermis during fibrogenesis. Together, these results suggest that both acute normal wound healing and chronic fibrotic scaring may share common EMT characteristics and underlying mechanisms such as basement membrane remodeling (partial breakdown), epithelial plasticity, and motility.

\section{Induction of EMT Features in Normal Full-Thickness Human Skin by Cytokines}

Because of the association between elevated inflammation and EMT in both acute and fibrotic wound healing, 

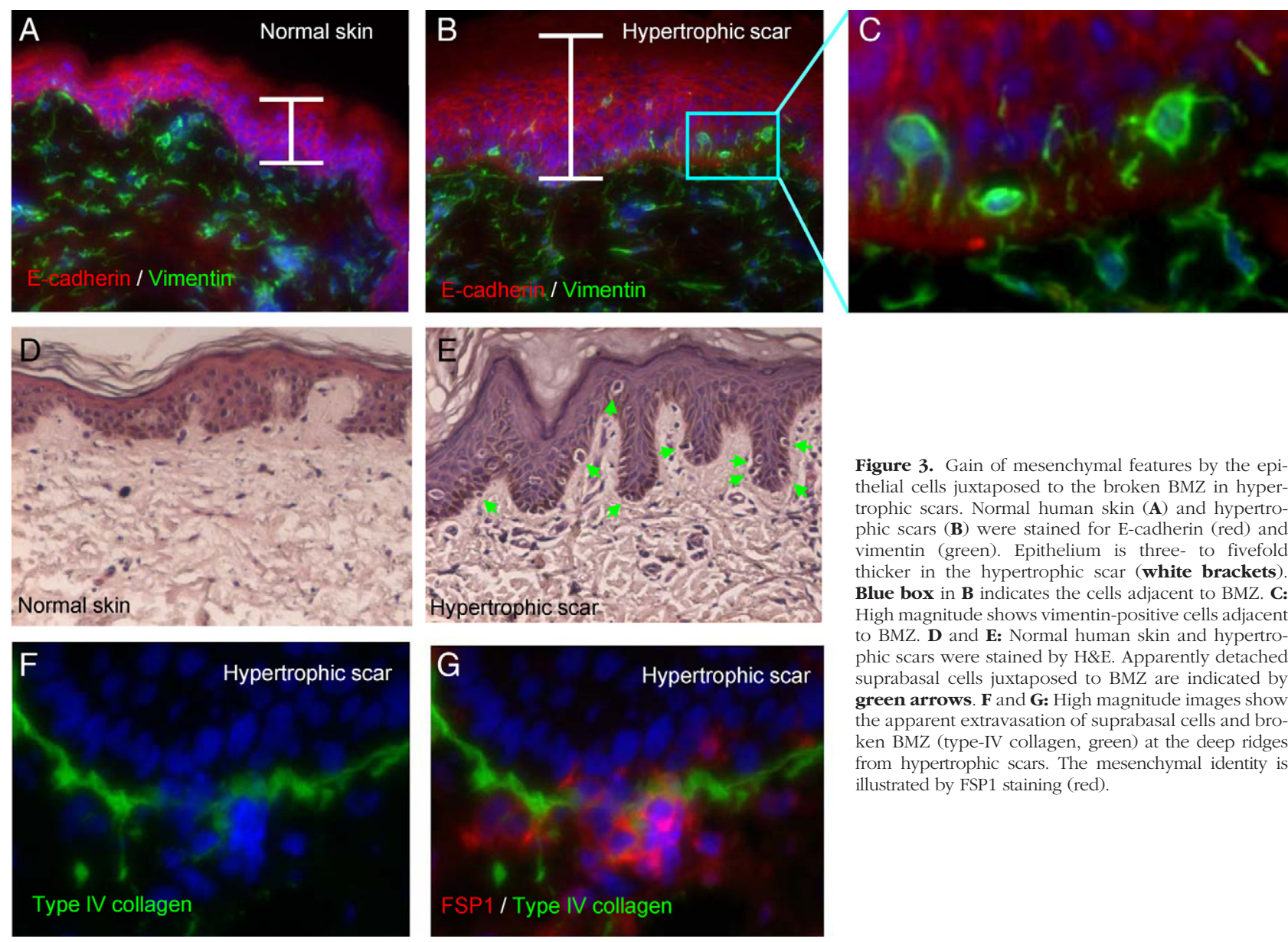

Figure 3. Gain of mesenchymal features by the epithelial cells juxtaposed to the broken BMZ in hypertrophic scars. Normal human skin (A) and hypertrophic scars (B) were stained for E-cadherin (red) and vimentin (green). Epithelium is three- to fivefold thicker in the hypertrophic scar (white brackets) Blue box in B indicates the cells adjacent to BMZ. C: High magnitude shows vimentin-positive cells adjacent to BMZ. D and E: Normal human skin and hypertrophic scars were stained by H\&E. Apparently detached suprabasal cells juxtaposed to BMZ are indicated by green arrows. F and G: High magnitude images show the apparent extravasation of suprabasal cells and broken BMZ (type-IV collagen, green) at the deep ridges from hypertrophic scars. The mesenchymal identity is illustrated by FSP1 staining (red).

we speculated that inflammatory cytokines may directly provoke EMT in human skin. To test the hypothesis, explants of normal full-thickness human skin (about 100 $\mathrm{mg}$ ) were incubated in basal DMEM together with TNF- $\alpha$ or TGF- $\beta 1$ at $4^{\circ} \mathrm{C}$ for 18 hours to allow penetration of these factors into the tissues. Then, the cultures were moved to $37^{\circ} \mathrm{C}$ with carbon dioxide for an additional 24 hours. The explants were assessed for EMT characteris-

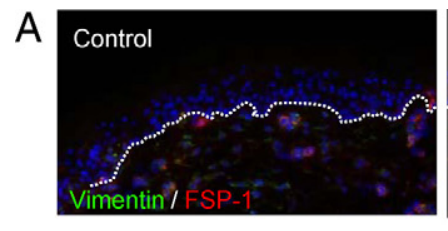

B

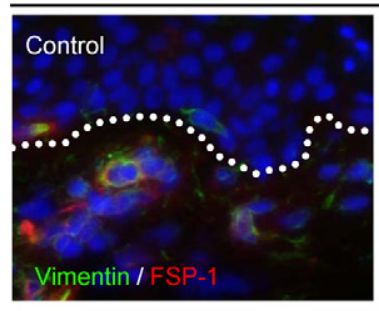

D

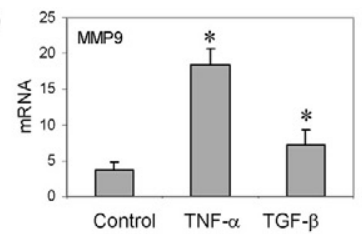

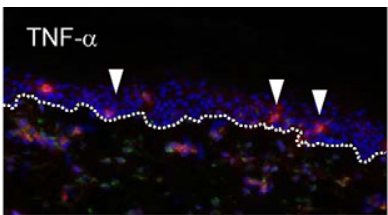

High Magnification
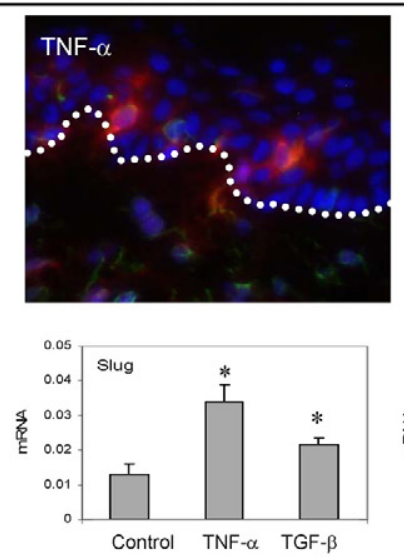
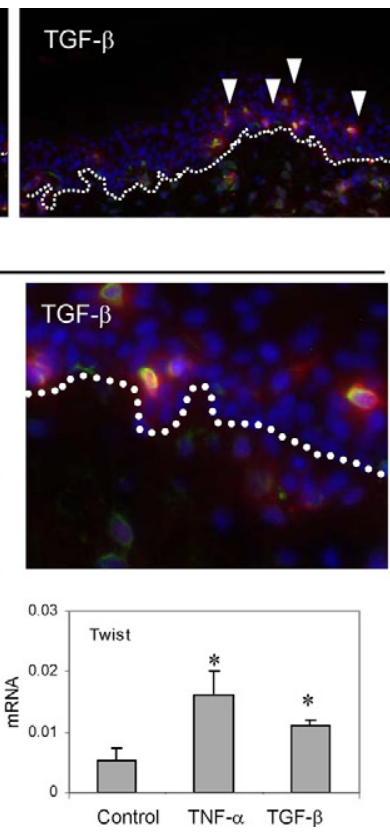

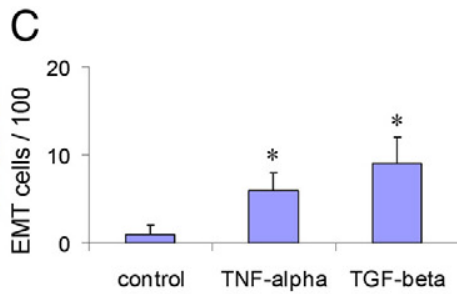

Figure 4. Induction of mesenchymal features in epidermis of the human skins by cytokines. Normal human skin explants were primed by TNF- $\alpha(10 \mathrm{ng} / \mathrm{ml})$ or TGF- $\beta 1(1 \mathrm{ng} / \mathrm{ml})$ for 18 hours at $4^{\circ} \mathrm{C}$, followed by culture at $37^{\circ} \mathrm{C}$ for additional 24 hours. A: Gain of mesenchymal characteristics was examined by expression of vimentin (IF staining, green) and FSP1 (red), indicated by white arrowheads BMZ is highlighted by white dotted lines. B: High magnification shows vimentin FSP-1 copositive cells in the epidermis treated by cytokines. C: Graphical representation of the occurrence of the EMTpositive cells in the epithelia in average of three views $\left({ }^{*} P<0.05\right.$ as significance by Student $t$ test). D: The mRNA levels were measured by qRT-PCR. 
A
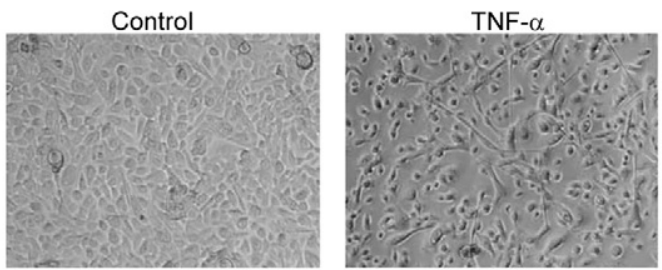

B
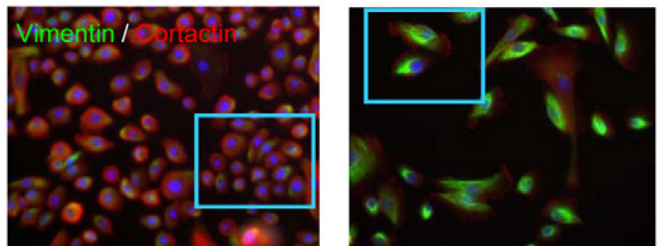

C
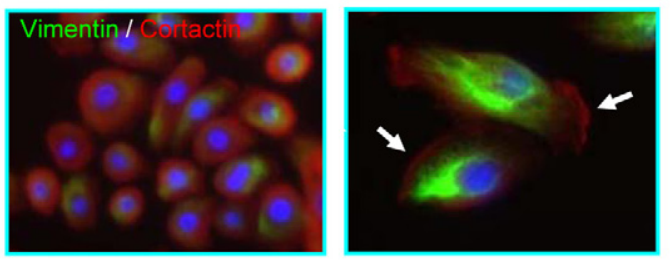

D

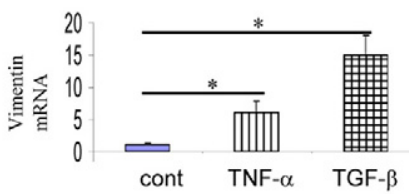

TNF- $\alpha-$

TGF- $\beta$ -

E

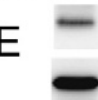

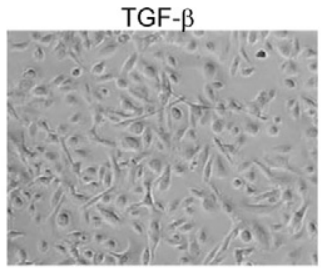
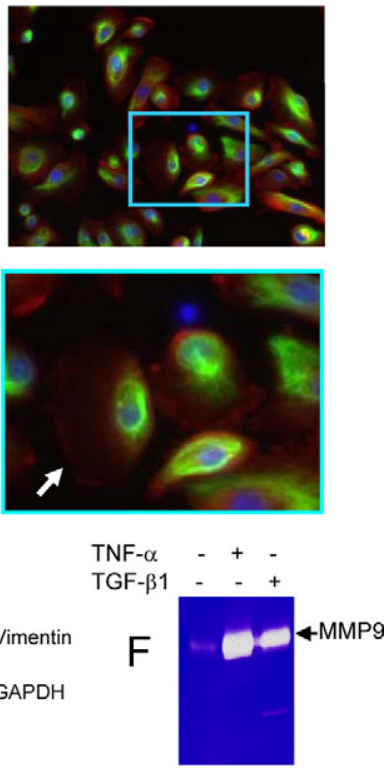

Figure 5. Induction of mesenchymal features by primary human skin keratinocytes under cytokine treatments. Primary keratinocytes were cultured in growth medium to near confluence. A: Plasticity of skin keratinocytes in mesenchymal morphology was evident after 24 hours treatment with TNF- $\alpha$ (10 ng/ml) or TGF- $\beta$ (1 $\mathrm{ng} / \mathrm{ml}$ ), as shown by phase contrast microscopy. B: The mesenchymal induction was demonstrated by expression of vimentin (IF staining, green) by the cells cultured for five days. Cortactin, predominantly expressed in epithelial cells, was stained in red; nuclei were stained by DAPI in blue. The details of morphology, as highlighted by the interior boxes, are illustrated in C. C: Lamellipodia are shown in high magnification and indicated by white arrows D: Expression of vimentin mRNA was measured by qRT-PCT analysis of the cells treated by cytokines for 24 hours $(n=3)$. E: Expression of vimentin was measured by Western blot analysis. GAPDH was used as loading control. F: MMP-9 secreted into the condition media was measured by gelatinolytic zymography. G: Dermal fibroblasts constitutively express vimentin (green). TGF- $\beta$ induces filamentous actin (phalloidin, red)
G

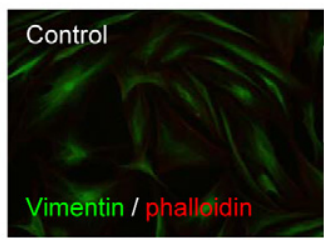

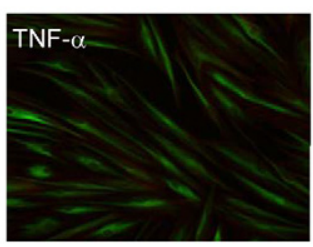

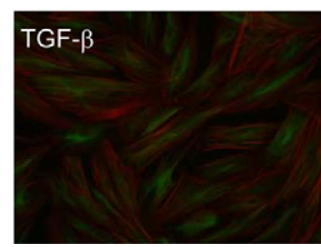

tics. In the control skin, FSP1- and vimentin-positive cells are largely absent from epithelia, but found in dermis as expected (Figure 4A). Under the stimulations of these cytokines, many epithelial cells, at their proximity to BMZ, express both FSP1 and vimentin, illustrating EMT induction (Figure 4, A and B). Using morphometric analysis we estimated the degree of EMT induction in human skin. On TNF- $\alpha$ treatment, the EMT-positive cell population rose from less that $1 \%$ in the control to roughly $5 \%$, whereas TGF- $\beta$ provided higher induction to about $7 \%$ (Figure $4 \mathrm{C})$. At higher magnification, we noticed that copositive cells occupied both suprabasal and spinous/granular layers of the epidermis under the cytokine stimulations (Figure 4B). MMP induction, a key feature of EMT, was induced in human skin mostly by TNF- $\alpha$, and in a less extent by TGF- $\beta$, as determined by quantitative RT-PCR (Figure 4D). Slug and twist, the transcription factors controlling EMT, were also induced by TNF- $\alpha$ and TGF- $\beta$ accordingly. These results explicitly demonstrate potential causative roles of innate inflammation, as represented by TNF- $\alpha$, and the fibrotic cytokines such as TGF- $\beta$, in induction of EMT features in human skin during acute wound healing and fibrogenesis.

\section{Primary Human Skin Keratinocytes Undergo EMT by Cytokine Stimulation}

Given the results of cytokine-induced EMT characteristics in full-thickness human skin, we attempted to recapitulate these features in primary keratinocytes. Epidermal keratinocytes were isolated from adult human skin. Under the treatment of TNF- $\alpha$ or TGF- $\beta$, cells displayed spindle-shaped body and "long-armed" intercellular connections, demonstrating morphological plasticity of epithelia cells under stress (Figure 5A). During the first 2 to 3 days of cytokine treatment, the transition of cell morphology from polygonal to spindle shapes is reversible, as demonstrated by time-lapse photography (data not shown). In the prolonged exposure to the cytokines for 4 to 5 days, the epithelial cells were scattered from patched clones and stably express mesenchymal-markers. As shown in Figure 5B, under TNF- $\alpha$ or TGF- $\beta$, most of the epithelial cells expressed vimentin, an intermediate filamentous cytoskeleton involved in migration of mesenchymal cells. Vimentin fibers were observed in the perinuclear regions, whereas cortactin, an organizer of filamentous actin, was found in the outreaching lamellapodia (Figure 

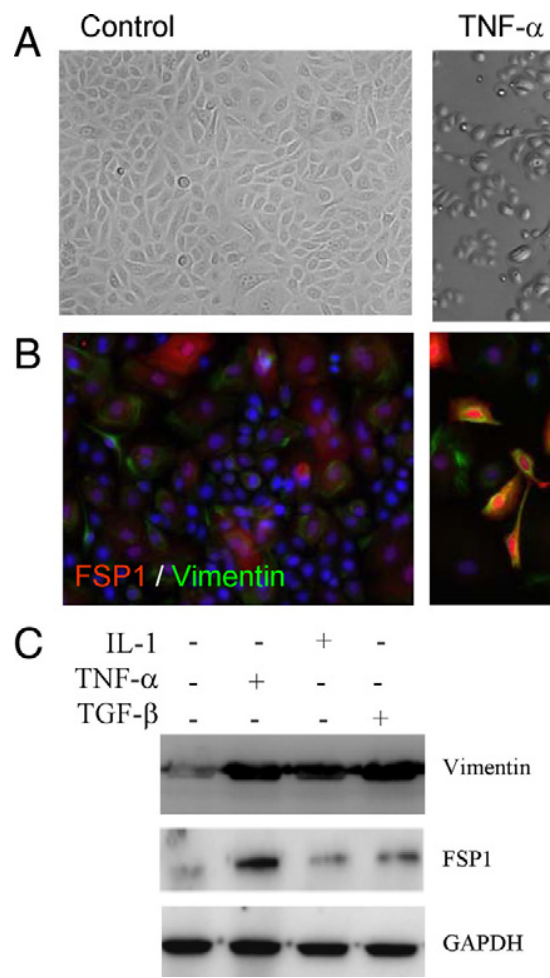

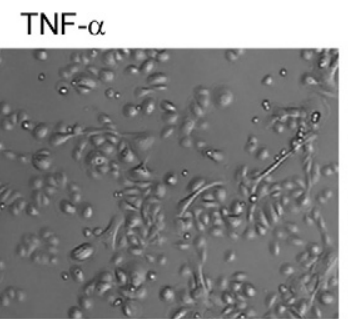

TGF- $\beta$

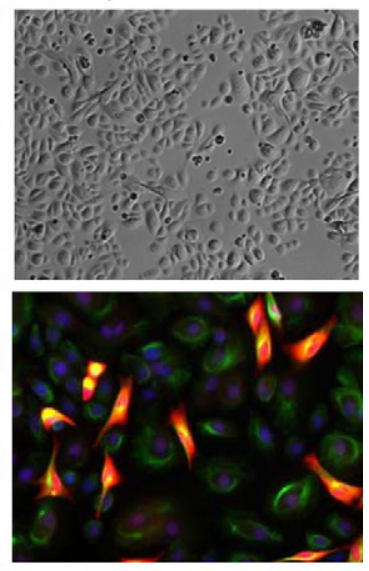

D

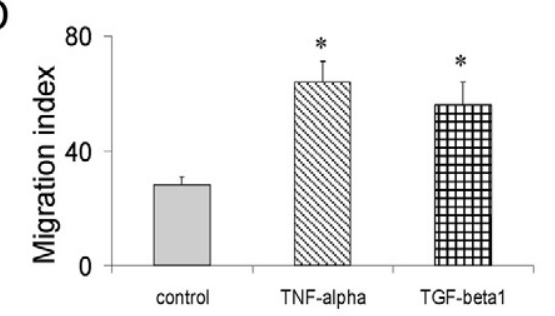

Figure 6. Heterogeneous mesenchymal inductions by neonatal keratinocytes. A: Cytokineinduced plasticity of the neonatal epidermal keratinocytes was demonstrated by phase contrast microscopy, after treatments for 3 days. B: Under TNF- $\alpha$, most of the epithelial cells are converted to vimentin (green) and FSP1 (red) double-positive cells (yellow). In response to TGF- $\beta 1$, two populations of mesenchymal-positive cells are emerged, either as the double-positive ones, or vimentin-positive/FSP-1-negative ones. C: Mesenchymal induction was measured by Western blot for vimentin and FSP1. D: Motility of the primary keratinocytes under mesenchymal transition was measured by in vitro wound healing, and determined by closure of the scratched tracks $\left(n=4,{ }^{*} P<0.05\right.$ as significance by Student $t$ test).
5, B and C, white arrows). These features are prominent characteristics of mesenchymal cells, demonstrating plasticity of the epithelial cells under the injury signals. We measured induction of vimentin mRNA by the primary keratinocytes. After 24 hours of treatment, the mRNA of vimentin was elevated 5.5- and 15-fold by TNF- $\alpha$ and TGF- $\beta$, respectively (Figure 5D). Induction of vimentin protein was also measured by Western blot analysis, which is consistent with its mRNA levels (Figure 5E). Expression of MMPs is another benchmark of EMT to facilitate cell migration. As measured by zymography, MMP-9, but not MMP-2, was massively induced by TNF- $\alpha$ and to a less extent by TGF- $\beta$ in the epithelial cells (Figure 5F). Expression of multiple MMPs by the keratinocytes under the injury signals, such as TNF- $\alpha$ and IL-1, in the keratinocytes may weaken the intercellular adhesions, and provoke ECM degradation to facilitate cell migration. ${ }^{10}$ Finally, the dermal fibroblasts (isolated from the same donors) constitutively expressed vimentin, which is seemingly independent of the cytokine regulation. Instead, TGF- $\beta$, but not TNF- $\alpha$, promoted F-actin formation in dermal fibroblasts (Figure 5G). These findings may also explain the histological findings of disrupted BMZ in our clinical tissue specimens.

We further evaluated human neonatal keratinocytes for their EMT potentials under the cytokine treatments. Within the first three days of culture and under cytokine treatments, the neonatal keratinocytes exhibited the similar plasticity as the adult epithelial cells as noted by reversible elongation of cell bodies and migratory phenotype (Figure 6A). In prolonged TNF- $\alpha$ treatment, most epithelial cells expressed both vimentin and FSP1 (Figure 6B). Of note is that FSP1, but not vimentin, was found in both nuclear and cytoplasmic compartments. However, under
TGF- $\beta 1$ treatment the cells were converted into two populations, some cells expressed both vimentin and FSP1, and others were vimentin-positive but FSP1-negative. The cytokine-induced expression of vimentin and FSP1 by primary keratinocytes was also confirmed by Western blot analysis. TNF- $\alpha, \mathrm{IL}-1$, and TGF- $\beta$ each could induce vimentin, whereas TNF- $\alpha$ massively induced FSP1 expression (Figure 6C). The essence of EMT is to empower epithelial cells into migration mode under extracellular challenges. After stimulation with inflammatory cytokines, both neonatal and adult keratinocytes exhibited scattering and migratory phenotypes. To confirm this notion, we performed in vitro wound healing assay. Keratinocytes were exposed to TNF- $\alpha$ or TGF- $\beta 1$ for 24 hours followed by scratch, and migration and closure of gaps were monitored by time lapse photography. As shown in Figure 6D, TNF- $\alpha$ or TGF- $\beta$ drives the keratinocyte migration, in line with expression of MMPs (data not shown). In conclusion, injury signals such as TNF- $\alpha, \mathrm{IL}-1$, and TGF- $\beta$ evoke mesenchymal characteristics in human keratinocytes and empower the cells into motile capacity.

\section{BMP-2 as a Downstream Mediator in the TNF- $\alpha$-Induced EMT}

Inspired by the well-established genetic pathway of spätzle/toll/dorsal/decapentaplegic in controlling EMT during gastrulation in fly embryonic development, we were interested in exploring the potential orthologic circuitry in the human skin keratinocytes and to test whether the TNF- $\alpha$-induced EMT is mediated by BMP in human skin and epithelial cells. First, we tested whether BMP-2 itself could initiate EMT features. After 24 hours exposure 

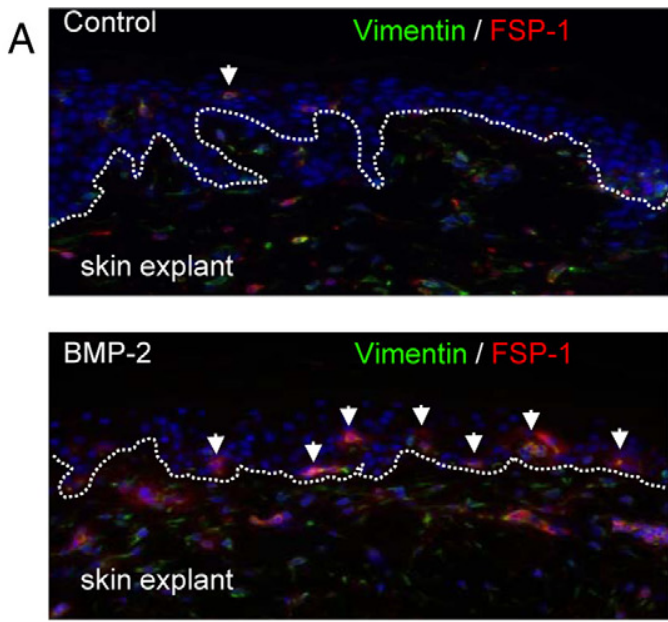

\section{B}
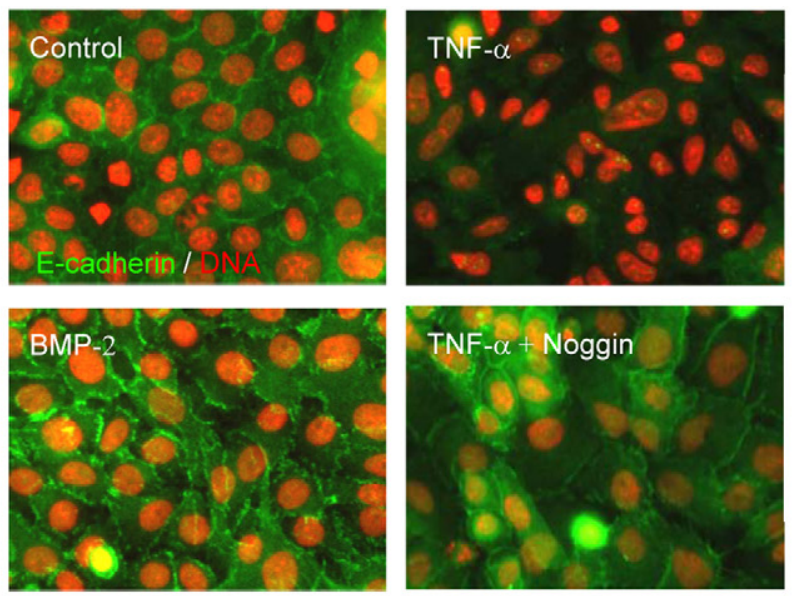

C
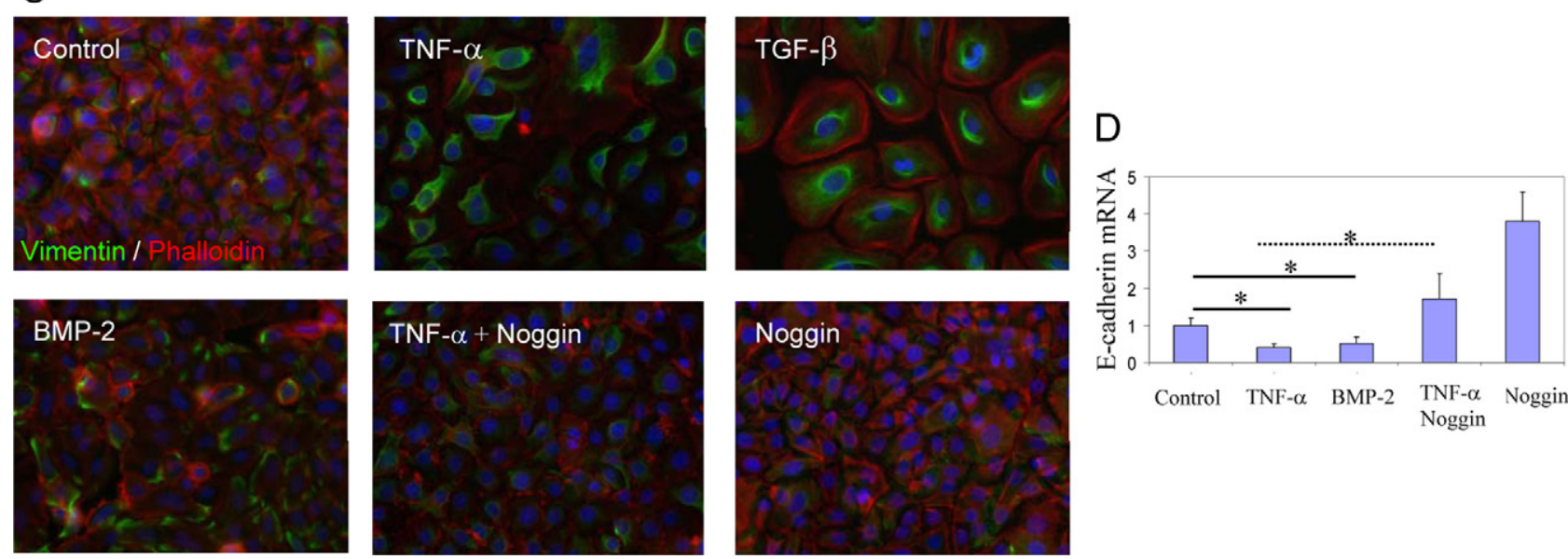

Figure 7. TNF- $\alpha$-induced EMT in human keratinocytes is mediated, in part, by induction of BMP-2. A: Adult full thickness human skin was explanted in DMEM and treated by BMP-2 or not for 24 hours. The mesenchymal transition in epithelial cells was detected by expression of vimentin (IF staining, green) and FSP1 (red), indicated by white arrows. BMZ was designated by dotted white lines. B: Participation of BMP2/4 in TNF- $\alpha$-induced EMT was demonstrated by blockage with noggin, an antagonist for BMP receptor. Primary keratinocytes were treated by BMP-2 ( $40 \mathrm{ng} / \mathrm{ml})$, TNF- $\alpha$ (10 ng/ml), and noggin (200 ng/ml) for five days, Loss of epithelial adhesion was measured by disassembly or alternation of E-cadherin (IF staining, green). Nuclei were highlighted by propidium iodide (IF staining, red). C: Mesechymal induction was measured by expression of vimentin (IF staining, green) and filamentous actin (phalloidin, red). D: Repression of E-cadherin by TNF- $\alpha$ and BMP-2, and restoration of E-cadherin by noggin were conducted by treatments of the cells for 24 hours, followed by qRT-PCR analysis $\left(n=3,{ }^{*}\right.$ statistical significance, $\left.P<0.05\right)$.

with BMP-2, many epithelial cells expressed both FSP1 and vimentin in explanted full thickness human skin (Figure 7A). Then, we measured whether BMP-2 can directly induce EMT in primary keratinocytes. Consistent with our previous data, under TNF- $\alpha$ treatment the intercellular E-cadherin boundary was largely abolished in the normal keratinocytes (Figure 7B). Noggin, an endogenous BMP antagonist, clearly impaired the TNF- $\alpha$-induced disassembly of E-cadherin and partially restored the normal keratinocyte sheets. BMP-2 alone disrupted the E-cadherin boundary as indicated by aggregated tight junctions and partial detachment of keratinocytes, although not to the extent of TNF- $\alpha$, suggesting additional pathways may participate in the TNF- $\alpha$-induced terminal EMT. In addition to restoring epithelial characteristics, the TNF- $\alpha$-induced gain of mesenchymal markers, such as expression of vimentin, was thoroughly impaired by noggin (Figure 7C). Consistent with its partial effect in downregulation of E-cadherin, BMP-2 alone mildly induced expression of vimentin protein in the primary keratino- cytes. At the mRNA levels, TNF- $\alpha$ or BMP-2 could suppress the expression of E-cadherin to about $50 \%$ in 20 hours treatment, as measured by qRT-PCR (Figure 7D). Noggin completely abolished the TNF- $\alpha$-induced suppression of E-cadherin and restored E-cadherin to the basal level. Adding noggin into the rich growth medium (HKGS in Epilife) eventually increased E-cadherin mRNA 4-folds higher than the control, suggesting presence of endogenous BMP-2/4 in the rich growth media. Finally, to strengthen the conclusion that BMP is a part of TNF- $\alpha$ pathway in EMT induction we also tested gremlin, another antagonist for BMP-2/4. Neonatal skin keratinocytes were cultured in growth medium or basal medium. After subconfluence the cultures were treated by TNF- $\alpha$ together with or without the antagonists for another 2 days. As shown, TNF- $\alpha$ induced extension of the epithelial cells, and such plasticity was impaired by gremlin and noggin (Supplemental Figure 2 at http://ajp.amjpathol.org). Finally, we measured whether cytokines including BMP-2 can drive epithelial cells migration in human skin ex- 
plants. Partial thickness human skin was explanted on top of plastic and treated by TNF- $\alpha$, TGF- $\beta$, and BMP-2. After four days of culture the epithelial cells migrated out as tightly adhered sheets. The cells at the front epithelial sheets were detached and expressed vimentin (see Supplemental Figure 3 at http://ajp.amjpathol.org). Taken together, we demonstrate that BMP-2/4 signaling may contribute, in part, to TNF- $\alpha$-induced both gain-of-mesenchymal and loss-of-epithelial characteristics of epidermal keratinocytes.

\section{TNF- $\alpha$ Induces Expression of BMP-2 and its Receptor in Primary Keratinocytes}

Given the results that BMP antagonists block the TNF- $\alpha-$ mediated EMT, as well as the evidence that BMP2 can directly induce EMT in human skin and the keratinocytes, we therefore addressed whether TNF- $\alpha$ can actually induce BMP-2 and its receptor. To identify this potential linkage we examined our Affymetrix DNA microarray data, by which the normal human skin was treated by TNF- $\alpha$ for 18 hours. As expected, TNF- $\alpha$ induced the expression of BMP-2 and the receptor, BMRP1A, in the full-thickness human skin (Supplemental Table 1 at $h$ ttp:// ajp.amjpathol.org). Many typical EMT genes such as MMP-9, fibronectin, Slug, and vimentin were also induced by TNF- $\alpha$ in human skin. TNF- $\alpha$-induced expression of BMPs and receptor in human skin was re-examined in the primary keratinocytes. As measured by qRT-PCR, TNF- $\alpha$ promptly induced expression of BMP-2 and its receptor BMR1A, but repressed E-cadherin in the keratinocytes (Figure 8). However, in dermal fibroblasts TNF- $\alpha$ failed to induce BMP-2 ligand, but increased the mRNA of BMPR1A. BMP2 could not significantly induce itself but increased its receptor in dermal fibroblasts. Taken together, these results indicate that the TNF- $\alpha$-induced EMT characteristics in human skin are mediated, at least in part, by induction of BMP-2 response machinery in both epithelial cells and dermal fibroblasts of the skin tissue.

\section{Discussion}

Although observed in tissue fibrosis of lung and kidney, and in cancer metastasis, it is still unknown whether EMT occurs during cutaneous wound healing and fibrosis of human skin. ${ }^{11,12}$ In this report, we first characterized the EMT-like features in acute and fibrotic wounds in human skin. The keratinocytes at the migrating tongue extensively expressed mesenchymal-specific markers. Adjacent to the wound bed, the epithelial cells in the deep rete ridges also readily attained mesenchymal markers. Then, we examined the association among inflammatory cytokines, EMT, and fibrogenesis in human hypertrophic scars, and found a tight connection between unresolved inflammation and EMT in skin fibrogenesis. To demonstrate the causal relationship, we recapitulated the basic features of EMT in explanted human skin by treatment with inflammatory cytokines. Furthermore, the full scale of
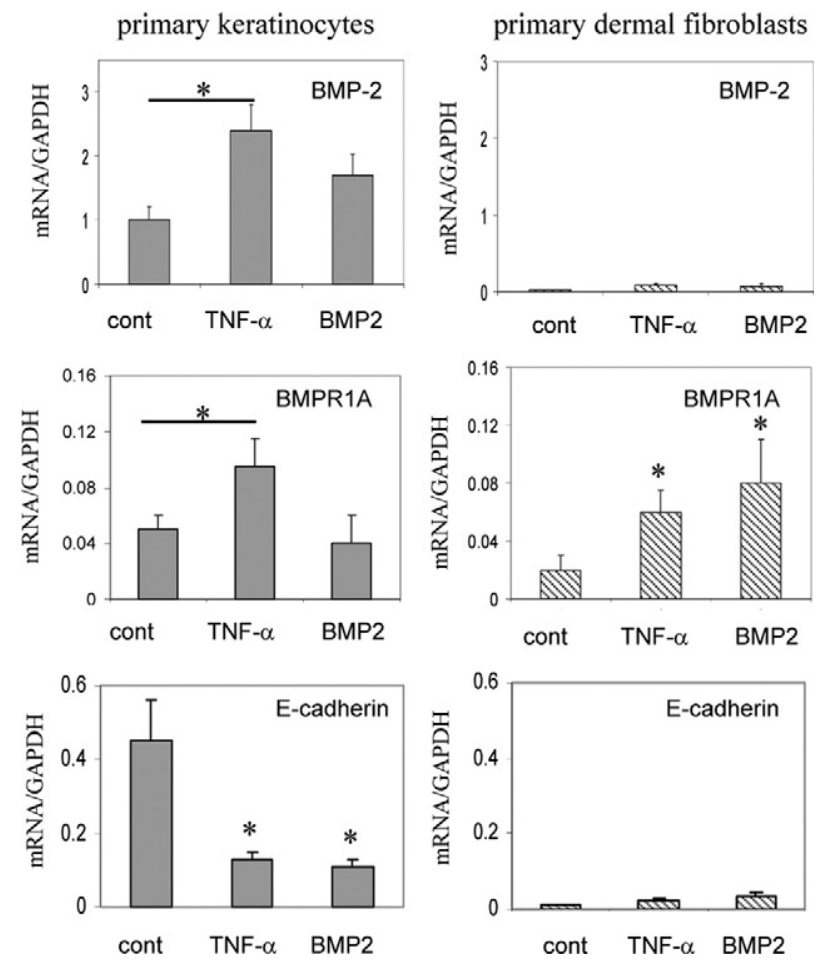

Figure 8. TNF- $\alpha$ induction of BMP-2 and BMPR1A. Primary epithelial cells and dermal fibroblasts were treated or not by TNF- $\alpha$ or BMP-2 for 20 hours. Expression of BMP-2, BMPR1A, and E-cadherin in mRNA was measured by qRT-PCR analysis $\left(n=3,{ }^{*} P<0.05\right)$.

EMT was readily induced by primary human keratinocytes under the cytokines. Finally, we found that the TNF- $\alpha$-induced EMT in human skin is mediated, in part, by induction of BMP-2/4 machinery. Hence, the injury induced mobilization of epithelial cells is likely through TNF- $\alpha$, and its downstream effector, BMP-2, to induce mesenchymal machinery in keratinocytes. The very similar mechanism may also apply to fibrotic wounds by which the unresolved inflammation evokes persistent EMT and fibrotic induction.

EMT was originally described as an important cellular programming that orchestrates formation of mesoderm during gastrulation. ${ }^{1,13}$ Accumulated evidence in last decade has uncovered EMT in many chronic diseases such as cancer progression and fibrotic diseases. ${ }^{3,14,15}$ The purpose of EMT, either in embryonic development or disease progression, is generally believed to mobilize epithelial cells into motility or invasion, through loss of cell-adhesion and polarity, and simultaneous gain of mesenchymal machinery such as formation of intermediate filaments, filopodia, and lamellopodia. This cellular reprogramming is initiated by diverse extracellular cues, from Spätzle in drosophila to Wnt and TGF- $\beta$ in mammals. ${ }^{16,17}$ The epithelial cells undergoing EMT are reprogrammed by two sets of circuitries, loss of epithelial tight junctions such as down-regulation of E-cadherin, and gain of mesenchymal machinery such as expression vimentin and FSP1. Extensive studies in the past decade have focused on addressing how tight junctions are dismantled in EMT. For instance, suppression of E-cadherin at the transcriptional level by Wnt or TGF- $\beta$ has been 
delineated in details, which is initiated by the ligandinducible activation of kinase pathways that modulate GTPase, Smads, PI3Ks, MAP kinases, $\beta$-catenin, and activate transcription factors including LEF-1, Snail, Slug, and Scatter, which ultimately lead to repression of Ecadherin gene. ${ }^{5}$ On the other hand, it is less clear how the mesenchymal genes are induced in the epithelial cells by diverse cytokines. A well-established case to understand how general mesenchymal genes are induced in epithelial cells has been attributed to the study of FSP1. Initially identified as a fibroblast specific protein, FSP1 has been widely used as a marker to indicate mesenchymal induction. ${ }^{18} \mathrm{~A}$ cis-element, called FTS-1/ CArG box, originally identified in FSP1 promoter, has been found in many mesenchymal genes including vimentin, $\alpha$-smooth muscle actin, aggrecan, type-I and -III collagen, TGF- $\beta$, and MMP-9. ${ }^{19}$ Thereafter, a complex of two proteins, CArG box-binding factor-A (CBF-A) and KRAB-associated protein 1 (KAP-1), has been found to bind this site. ${ }^{20}$ Because this cis-element is commonly found among many mesenchymal genes, induced by TNF- $\alpha$, including FSP1, vimentin, and MMP-9, it would be worth addressing whether and how TNF- $\alpha$ activates FTS$1 / \mathrm{CArG}$ box and its binding factors in mesenchymal induction.

The proximity of the epithelial cells, in both the migrating tongue and the deep ridges, to the wound bed, suggests possible diffusing factors, such as inflammatory cytokines as a hierarchal inducer in EMT induction. In this report we present evidence demonstrating TNF- $\alpha$ in induction of EMT-like process in human skin and primary keratinocytes. The property of TNF- $\alpha$-induced EMT in human skin and primary keratinocytes is supported at multiple levels. First, TNF- $\alpha$ up-regulates mesenchymal markers such as FSP1 and vimentin and mildly downregulates E-cadherin as well. Second, TNF- $\alpha$ elevates Twist and Slug, the key transcription factors responsible for down-regulation of E-cadherin, in both explanted human skin and primary keratinocytes. Third, TNF- $\alpha$-treated keratinocytes are highly motile, as an ultimate consequence of EMT. Different from the efforts of TGF- $\beta$, the EMT induced by TNF- $\alpha$ is associated with expression of multiple MMPs, which may facilitate disassociation of cellular junctions and migration. In fact, in some cases MMPs may sufficiently induce EMT, presumably by activation of a particular GTPase. ${ }^{21}$

Many growth factors can induce EMT by various models from cancer cells to animal injury, ${ }^{22}$ but whether and how pro-inflammatory cytokines propagate EMT during wound healing of human skin has not yet been fully addressed. From the view of orthological comparison, the EMT induced by Spätzle/Toll/Dorsal/Snail in gastrulation of fly is apparently comparable with TNF- $\alpha$ or IL-1/their receptors/NF- $\kappa \mathrm{B} / \mathrm{Snail}$ in mammalian cells. Further, the Toll/Dorsal system is applied in both embryonic development and innate immunity in the wound healing of adult fly. ${ }^{17,23}$ Thus, evolutionary conservation and functional redundancy implies the role of innate immunity in controlling EMT during wound healing. One end point of the Toll/Dorsal genetic pathway in drosophila is decapentaplegic (Dmel/dpp), which is orthologically related to
BMP or TGF- $\beta{ }^{16}$ This speculation led us to examine the induction of BMP system by TNF- $\alpha$. First, from genomic DNA Microarray data we noticed that TNF- $\alpha$ could induce BMP-2 and the receptor BMPR1A in human skin. Then, we confirmed that both BMP-2/4 and their receptor were expressed by keratinocytes, but not the dermal fibroblasts, under TNF- $\alpha$ stimulation, implying a potential autocrine loop in epithelial activation. How BMP-2 and its receptor are up-regulated in human skin is unknown, but in chondrocytes, TNF- $\alpha$ was shown to induce BMP-2 through mRNA stabilization and transcriptional up-regulation. ${ }^{24}$ We uncovered a potential role for BMP in skin wound healing, but the underlying mechanism may differ from TNF- $\alpha$. First, TNF- $\alpha$, but not BMP-2, induces many MMPs. Second, although BMP-2 suppressed the mRNA of E-cadherin to the same level as TNF- $\alpha$, the morphogen could not fully disassemble E-cadherin from the cell boundary. Instead, under BMP-2 treatment, E-cadherin was aggregated into discontinued bodies in lamellipodia. In the same respect, BMP-2 only partially induces vimentin filaments in comparison with the scale of TNF- $\alpha$. On the other hand, Noggin and Gremlin blocked TNF- $\alpha-$ induced EMT features, suggesting that BMP-2/4 and additional signaling pathway(s) under TNF- $\alpha$ are both required for the TNF- $\alpha$-induced EMT.

It is not known whether the same mechanism and inducers for EMT in hypertrophic scars are used as those for acute wound healing. Because the persistent inflammation is tightly associated with fibrogenesis, it would be reasonable to assume so. Such speculation was supported by our data showing elevated TNF- $\alpha$ and EMT features in scarring tissues. First, twist and slug are upregulated in the scar region, along with the elevated TNF- $\alpha$. Second, the increased mesenchymal markers such as fibronectin, N-cadherin, FSP1, and vimentin are expressed inversely with decreased E-cadherin in the scar region. Third, classic fibrotic features such as $\alpha$-SMA and type-I collagen are also profoundly enhanced in the scar region. All of these are in association with the EMT features. Although EMT has been demonstrated in fibrosis of the kidney and lung by animal models, ${ }^{3,11,25}$ whether EMT actually contributes to skin fibrosis is not well addressed. Fibrosis is characterized by proliferation of myofibroblasts and interstitial ECM. In the first 1 to 3 days of treatment with TNF- $\alpha$, BMP-2, or TGF- $\beta$, confluent keratinocytes undergo spindle-like changes with long cytoplasmic extensions, particularly in the primary adult keratinocytes. Under the prolonged treatment, for 3 to 6 days, many keratinocytes undergo terminal transition with well-developed philopodia. In essence, the EMT-programmed cells are not like typical myofibroblasts; this is further supported by the evidence of lack of expression of $\alpha$-SMA in the EMT-positive cells (data not shown). The actual lineage of the end-point EMT from the primary keratinocytes is not known, but they can be regarded as highly motile and keratinocytes with mesenchymal features. However, in tissue staining we rarely noticed the colocalization of both E-cadherin and vimentin/FSP-1 cells in epithelial layers. This is understandable, because gain-of-mesenchymal and loss-of-epithelial markers occurs simultaneously, leaving little window to trap the tran- 
sition process. However, such dynamic transition has been recapitulated by in vitro experiment. And it can be additionally demonstrated by lineage tracing in transgenic mice, by which their epithelial cells have been "permanently" marked.

Cells migrate in two different manners. The first one is chemotaxis, the bodily movement of singular cells, driven by the concentrations of phenomenon and cytokines. This type of migration is instant, and the locomotion is propelled by built-in machinery. Mesenchymal cells migrate in this way, which relies on interactions of integrin to matrix, and myosin to F-actins, which is conducted by signal transduction involving small GTPase. The second type relies on trans-differentiation or cellular transition, applied by epithelial cell migration. At the beginning the tight junctions between cells have to be partially dissociated, or loosened. Then, the epithelial cells have to build up migration machinery with mesenchymal characteristics. The mesenchymal machinery includes extracellular matrix such as fibronectin, the degradation enzymes such as MMPs, receptors such as integrins, intermediate actin filaments such as vimentin and myosin chains, etc. The intermediate actin filaments, such as vimentin, in filopodia elongate at the growth ends and disassemble and release the G-actin monomers at their tailing ends, resulting in filopodial protrusion. MMPs, induced by TNF$\alpha / \mathrm{IL}-1$, may facilitate the cell migration.

We have to appreciate the diversity of cellular residents in human skin, which limits our capability to make conclusive remarks about the lineage and/or origin of cells. The extent and spectrum of induction of mesenchymal markers in EMT is highly variable, relying on the subtypes of initial epithelial cells. For instance, in this study we did not observe trans-differentiation of human keratinocytes into typical fibroblasts or myofibroblasts. Further, melanocytes and Langerhans cells have also been shown to express vimentin. ${ }^{26,27}$ Therefore, we approached our interpretations and conclusions with caution, particularly for the EMT in skin fibrosis.

\section{Acknowledgment}

We thank Dr. Yujiro Kida for feedback and comments.

\section{References}

1. Hay ED: An overview of epithelio-mesenchymal transformation. Acta Anat (Basel) 1995, 154:8-20

2. Levayer R, Lecuit T: Breaking down EMT. Nat Cell Biol 2008, 10:757-759

3. Zeisberg M, Kalluri R: Fibroblasts emerge via epithelial-mesenchymal transition in chronic kidney fibrosis. Front Biosci 2008, 13:6991-6998

4. Xue C, Plieth D, Venkov C, Xu C, Neilson EG: The gatekeeper effect of epithelial-mesenchymal transition regulates the frequency of breast cancer metastasis. Cancer Res 2003, 63:3386-3394

5. Kalluri R, Neilson EG: Epithelial-mesenchymal transition and its implications for fibrosis. J Clin Invest 2003, 112:1776-1784

6. Singer AJ, Clark RA: Cutaneous wound healing. N Engl J Med 1999, 341:738-746

7. Chen JD, Lapiere JC, Sauder DN, Peavey C, Woodley DT: Interleu- kin-1 alpha stimulates keratinocyte migration through an epidermal growth factor/transforming growth factor-alpha-independent pathway. J Invest Dermatol 1995, 104:729-733

8. Castagnoli C, Trombotto C, Ondei S, Stella M, Calcagni M, Magliacani G, Alasia ST: Characterization of T-cell subsets infiltrating post-burn hypertrophic scar tissues. Burns 1997, 23:565-572

9. Radisky DC, Kenny PA, Bissell MJ: Fibrosis and cancer: do myofibroblasts come also from epithelial cells via EMT? J Cell Biochem 2007, 101:830-839

10. Han YP, Tuan TL, Hughes M, Wu H, Garner WL: Transforming growth factor-beta-and tumor necrosis factor-alpha-mediated induction and proteolytic activation of MMP-9 in human skin. J Biol Chem 2001, 276:22341-22350

11. Willis BC, Borok Z: TGF-beta-induced EMT: mechanisms and implications for fibrotic lung disease. Am J Physiol Lung Cell Mol Physiol 2007, 293:L525-L534

12. Yang J, Liu Y: Dissection of key events in tubular epithelial to myofibroblast transition and its implications in renal interstitial fibrosis. Am J Pathol 2001, 159:1465-1475

13. Shook D, Keller R: Mechanisms, mechanics and function of epithelialmesenchymal transitions in early development. Mech Dev 2003, 120:1351-1383

14. Huber MA, Azoitei N, Baumann B, Grunert S, Sommer A, Pehamberger $H$, Kraut N, Beug H, Wirth T: NF-kappaB is essential for epithelialmesenchymal transition and metastasis in a model of breast cancer progression. J Clin Invest 2004, 114:569-581

15. Kida Y, Asahina K, Teraoka H, Gitelman I, Sato T: Twist relates to tubular epithelial-mesenchymal transition and interstitial fibrogenesis in the obstructed kidney. J Histochem Cytochem 2007, 55:661-673

16. Gelbart WM: The decapentaplegic gene: a TGF-beta homologue controlling pattern formation in Drosophila. Development 1989, 107 Suppl:65-74

17. Morisato D, Anderson KV: Signaling pathways that establish the dorsal-ventral pattern of the Drosophila embryo. Annu Rev Genet 1995, 29:371-399

18. Strutz F, Okada H, Lo CW, Danoff T, Carone RL, Tomaszewski JE, Neilson EG: Identification and characterization of a fibroblast marker: fSP1. J Cell Biol 1995, 130:393-405

19. Iwano M, Plieth D, Danoff TM, Xue C, Okada H, Neilson EG: Evidence that fibroblasts derive from epithelium during tissue fibrosis. J Clin Invest 2002, 110:341-350

20. Venkov CD, Link AJ, Jennings JL, Plieth D, Inoue T, Nagai K, Xu C, Dimitrova YN, Rauscher FJ, Neilson EG: A proximal activator of transcription in epithelial-mesenchymal transition. J Clin Invest 2007, 117:482-491

21. Radisky DC, Levy DD, Littlepage LE, Liu H, Nelson CM, Fata JE, Leake D, Godden EL, Albertson DG, Nieto MA, Werb Z, Bissell MJ: Rac $1 \mathrm{~b}$ and reactive oxygen species mediate MMP-3-induced EMT and genomic instability. Nature 2005, 436:123-127

22. Thiery JP: Epithelial-mesenchymal transitions in development and pathologies. Curr Opin Cell Biol 2003, 15:740-746

23. Smallhorn M, Murray MJ, Saint R: The epithelial-mesenchymal transition of the Drosophila mesoderm requires the Rho GTP exchange factor Pebble. Development 2004, 131:2641-2651

24. Fukui N, Ikeda Y, Ohnuki T, Hikita A, Tanaka S, Yamane S, Suzuki R, Sandell LJ, Ochi T: Pro-inflammatory cytokine tumor necrosis factoralpha induces bone morphogenetic protein-2 in chondrocytes via mRNA stabilization and transcriptional up-regulation. J Biol Chem 2006, 281:27229-27241

25. Thomson S, Buck E, Petti F, Griffin G, Brown E, Ramnarine N, Iwata KK, Gibson N, Haley JD: Epithelial to mesenchymal transition is a determinant of sensitivity of non-small-cell lung carcinoma cell lines and xenografts to epidermal growth factor receptor inhibition. Cancer Res 2005, 65:9455-9462

26. de Waal RM, Semeijn JT, Cornelissen MH, Ramaekers FC: Epidermal Langerhans cells contain intermediate-sized filaments of the vimentin type: an immunocytologic study. J Invest Dermatol 1984, 82:602-604

27. Si SP, Tsou HC, Lee X, Peacocke M: Cultured human melanocytes express the intermediate filament vimentin. J Invest Dermatol 1993, 101:383-386 